\title{
Contribution of a tyrosine-based motif to cellular trafficking of wild-type and truncated NPY $Y_{1}$ receptors
}

\author{
Sandra Lecat ${ }^{\mathrm{b}, 1}$, Moussa Ouédraogo ${ }^{\mathrm{a}, 1}$, Thomas Cherrier $^{\mathrm{a}}$, Fanny Noulet ${ }^{\mathrm{a}}$, Philippe Rondé ${ }^{\mathrm{a}}$, Nicole Glasser ${ }^{\mathrm{a}}$, \\ Jean-Luc Galzi ${ }^{\mathrm{b}}$, Yves Mely ${ }^{\mathrm{a}}$, Kenneth Takeda ${ }^{\mathrm{a}}$, Bernard Bucher ${ }^{\mathrm{a}, *}$ \\ a UMR 7213, CNRS/Université de Strasbourg, Laboratoire de Biophotonique et Pharmacologie, Faculté de Pharmacie, 74 route du Rhin, BP 60024,67401 Illkirch, France \\ ${ }^{\mathrm{b}}$ Institut de Recherche de l'Ecole de Biotechnologie de Strasbourg, FRE 3211, Ecole Supérieure de Biotechnologie de Strasbourg, Boulevard Sébastien Brant, 67412 Illkirch, France
}

\section{A R T I C L E I N F O}

Article history:

Received 19 July 2010

Accepted 5 September 2010

Available online 15 September 2010

\section{Keywords:}

Neuropeptide $Y$

$\mathrm{Y}_{1}$ receptor

G protein-coupled receptors

Internalization

Constitutive internalization

Recycling

\begin{abstract}
A B S T R A C T
The human NPY $Y_{1}$ receptor undergoes fast agonist-induced internalization via clathrin-coated pits then recycles back to the cell membrane. In an attempt to identify the molecular determinants involved in this process, we studied several C-terminal truncation mutants tagged with EFGP. In the absence of agonist, $\mathrm{Y}_{1}$ receptors lacking the last $32 \mathrm{C}$-terminal amino acids $\left(\mathrm{Y}_{1} \Delta 32\right)$ are constitutively internalized, unlike full-length $Y_{1}$ receptors. At steady state, internalized $Y_{1} \Delta 32$ receptors co-localize with transferrin, a marker of early and recycling endosomes. Inhibition of constitutive internalization of $Y_{1} \Delta 32$ receptors by hypertonic sucrose or by co-expression of Rab5aS34N, a dominant negative form of the small GTPase Rab5a or depletion of all three isoforms of Rab5 indicates the involvement of clathrin-coated pits. In contrast, a truncated receptor lacking the last $42 \mathrm{C}$-terminal amino acids $\left(\mathrm{Y}_{1} \Delta 42\right)$ does not constitutively internalize, consistent with the possibility that there is a molecular determinant responsible for constitutive internalization located in the last 10 amino acids of $Y_{1} \Delta 32$ receptors. We show that the agonist-independent internalization of $Y_{1} \Delta 32$ receptors involves a tyrosine-based motif YXXФ. The potential role of this motif in the behaviour of full-length $\mathrm{Y}_{1}$ receptors has also been explored. Our results indicate that a C-terminal tyrosine-based motif is critical for the constitutive internalization of truncated $Y_{1} \Delta 32$ receptors. We suggest that this motif is masked in full-length $Y_{1}$ receptors which do not constitutively internalize in the absence of agonist.
\end{abstract}

(c) 2010 Elsevier Inc. All rights reserved.

\section{Introduction}

Neuropeptide Y (NPY) is widely distributed in the central and peripheral nervous systems. The actions of NPY are mediated by a family of four G protein-coupled receptors (GPCRs) with seven $\alpha$ helical transmembrane segments termed NPY $Y_{1}, Y_{2}, Y_{4}$, and $Y_{5}$. All four receptors are negatively coupled to adenylyl cyclase. We reported previously that the rapid desensitization of human $Y_{1}$ receptors following agonist exposure results from rapid clathrin-dependent internalization into an endosomal recycling compartment [1]. In contrast, $\mathrm{Y}_{4}$ receptors are resistant to agonist-induced desensitization and internalization [2], and $\mathrm{Y}_{2}$ receptors either do not internalize or do so only very slowly $[1,3]$. The internalization of GPCRs is considered to be a ubiquitous process that follows agonist-mediated activation, with

Abbreviations: NPY, neuropeptide Y; EGFP, enhanced green fluorescent protein; GPCR, $G$ protein-coupled receptor; $\mathrm{G}_{\mathrm{i} / \mathrm{o}}$, inhibitory GTP binding protein of adenylyl cyclase; HEK, human embryonic kidney; SP, signal peptide; LIC, ligation independent cloning; PBS, phosphate buffered saline; BSA, bovine serum albumin.

* Corresponding author. Laboratoire de Biophotonique et Pharmacologie, UMR 7213, Faculté de Pharmacie, 74 route du Rhin, BP 60024, 67401 Illkirch, France. Tel.: + 33368 8542 66; fax: + 33368854313 .

E-mail address: bernard.bucher@unistra.fr (B. Bucher).

1 These authors contributed equally to the work. internalized GPCRs being either recycled to the cell surface or degraded in lysosomes [4].

In many previous studies of other GPCRs, the C-terminal cytoplasmic tail was found to be essential for agonist-induced internalization [5-11]. The C-terminus of GPCRs is also a site for G protein-coupled receptor kinase (GRK)-mediated phosphorylation and arrestin interactions [12]. Recently, truncated rat $Y_{1}$ receptors have been reported to undergo agonist-independent constitutive internalization based on confocal microscopy (co-localization with transferrin-positive early and recycling endosomes) [13]. However, the molecular determinants of this internalization were not demonstrated [13]. In an attempt to identify the residues triggering agonistinduced internalization of human $Y_{1}$ receptors we recently analyzed several $Y_{1}$ mutants having C-terminal truncations of different lengths [14]. In the absence of agonist challenge, at $37^{\circ} \mathrm{C}$, only one of these mutants $\left(\mathrm{Y}_{1} \Delta 32\right)$ is weakly present at the plasma membrane, while being clearly present in punctate structures in the cytoplasm. We report here the characterization of the human $Y_{1} \Delta 32$ receptor and show that it is constitutively internalized.

Several constitutively internalized GPCRs have been previously reported. For example, constitutively active mutants (CAMs) are often constitutively internalized [15]. Agonist-independent constitutive internalization has also been described for wild-type GPCRs, including 
thromboxane $A_{2 b}$ receptors [16] and $\alpha_{1 a}$-adrenergic receptors [17]. A truncated protease-activated receptor-1 (PAR1) mutant containing an intact tyrosine-based C-terminal motif constitutively internalized, whereas the same truncation mutant with tyrosine and leucine replaced by alanine in the C-terminal motif failed to internalize [18]. Indeed, tyrosine-based sorting signals corresponding to a YХХФ motif ( $\mathrm{Y}$ denotes tyrosine, $\mathrm{X}$ is any amino acid and $\Phi$ is an amino acid with a bulky hydrophobic side group such as leucine, isoleucine or methionine) [19] have been implicated in directing protein localization to various intracellular compartments including endosomes and are capable of mediating rapid internalization from the plasma membrane into endosomes.

In the present study, we set up an assay to measure constitutive internalization based on antibody labeling of receptors at the cell surface, followed by a quantitative FACS analysis. Data from this assay are confirmed by confocal image analysis. Our results indicate that the truncation of the last 32 amino acids in the C-terminus of human $\mathrm{Y}_{1}$ receptors results in agonist-independent constitutive internalization via clathrin-coated pits. We show that this behaviour of $Y_{1} \Delta 32$ receptors involves a tyrosine-based signal motif in the C-terminus. Finally, our data also suggest that this tyrosine-based motif has a role in the fast recycling of the full-length human $Y_{1}$ receptor following agonist-dependent internalization.

\section{Materials and methods}

\subsection{Cell culture, cDNA constructs, expression and selection}

Control and transfected HEK293 cells were cultured to 80\% confluence in T-75 flasks in MEM with Earle's salt supplemented with $10 \%$ fetal calf serum, $2 \mathrm{mM}$ glutamine and 1\% antibiotics (penicillin/ streptomycin). cDNA of the human NPY $Y_{1}$ receptor was kindly provided by Prof. H. Herzog (Garvan Institute, Sydney, Australia). The $\mathrm{Y}_{1}$ C-terminal amino acid sequences of the truncated and mutated variants we generated and used in this study are given in Table 1. Construction of the pCEP4-SP-EGFP-hNPY $\mathrm{Y}_{1}$ vector (EGFP fused to the $\mathrm{NH}_{2}$-terminal) has been previously described [1]. The cloning scheme for the C-terminus $\Delta 32$ and $\Delta 42$ deletions was as follows: digestion of pCEP4-SP-EGFP-hNPY $\mathrm{Y}_{1}$ by Not1 and BamH1 to remove the SP-EGFP-hNPY $Y_{1}$ insert; PCR amplification of the appropriate SPEGFP-hNPY $Y_{1} \Delta 32$ and $\Delta 42$ using pCEP4-SP-EGFP-hNPY $Y_{1}$ as bait, with a $5^{\prime}$-primer containing a Not1 site upstream of the Signal Peptide (SP) sequence and 3'-primers containing a BamH1 site downstream of the $\mathrm{Y}_{1}$ sequence; insertion of the [Not1-BamH1] PCR-amplified SPEGFP-hNPY $Y_{1} \Delta 32$ or $\Delta 42$ fragment into the digested pCEP4-[Not1BamH1] vector. The sequence of the deletion mutant terminates with Leu-Ala, corresponding to an Nhe1 site in the 3'-primer of the $\Delta 32$ or $\triangle 42$ DNA constructs. The 5'-primer used for PCR was ctgggtaccagctgctagc and hybridized upstream of the SP sequence in pCEP4-SP-EGFPhNPY $Y_{1}$ (the Not1 site is not in the primer). The 3'-primers were gagaagcccggtggatcctcaTCAagctagCATGGCTATTGTTTCATAATCATC for SP-EGFP-hNPY $\mathrm{Y}_{1} \Delta 32$ and gagaagcccggtggatcctcaTCAagctagcGACCGGAAATCACAAAAGTTGAAG for SP-EGFP-hNPY Y ${ }_{1} \Delta 42$. The underlined sequences correspond to restriction sites, the sequence in italics is the Leu-Ala coding region and the uppercase sequence is the receptor sequence. The cloning scheme for the pCEP4-SP-EGFP-NPY $\mathrm{Y}_{1} \Delta 32^{\mathrm{Y} 347 \mathrm{~F}}$ receptor was the same as for $\mathrm{Y}_{1} \Delta 32$ except that the TAT nucleotide sequence encoding Tyr347 was replaced by TTT (encoding Phe) directly in the 3'-primer used for amplification of the insert (gagaagcccggtggatcctcaTCAagctagCATGGCTATTGTTTCaaaATCATC; where the underlined sequence corresponds to the nucleotide encoding Phe). Similarly, the cloning scheme for the pCEP4-SPEGFP-NPY $Y_{1} \Delta 32^{\mathrm{Y} 347 \mathrm{~A} / 1350 \mathrm{~A}}$ receptor was performed using the $3^{\prime}-$ primer directly containing the mutations for PCR amplification of the insert (gagaagcccggtggatcctcaTCAagctagCATGGCTGCTGTTTCAGCATCATCATC; where the underlined sequences correspond to the mutations).

The cloning scheme for the pmRFP1-Rab5S34N-C2 vector was as follows: digestion of the pEGFP-C2-Rab5S34N vector (kindly provided by Dr. M. Zerial, Max Planck Institute, Dresden, FRG) by Nhe1 and EcoR1 to remove the EGFP insert; PCR amplification of the mRFP1 gene using the pRSETB-mRFP1 vector as a bait (kindly provided by $\mathrm{R}$. Tsien; [20]) with a $5^{\prime}$ primer (GTCAGATCCGCTAGCTCGCCACCatggcctcctccgaggacgt) containing a Nhe1 site (underlined) upstream of the mRFP1 sequence (in lowercase) and with a $3^{\prime}$ primer (GGGAATTCggcgccggtggagtggcggccct) containing a EcoR1 site (underlined) downstream of the mRFP1 sequence (in lowercase) and such that the mRFP1 will be in frame with the Rab5S34N sequence; insertion of the [Nhe1-EcoR1] PCR-amplified mRFP1 fragment into the digested p[Nhe1-EcoR1]-C2-Rab5S34N vector. All constructions were verified by sequencing. Stably transfected cells were established by selection with hygromycin.

\subsection{RNA interference}

Sense and antisense RNA oligonucleotides protected by two 3'overhang (2'deoxy) thymidine (dT) directed against human Rab5a, Rab5b and Rab5c were purchased from QIAGEN. The selected target sequences were specific for human Rab5a (5'-AAAGGAATCAGTGTTGTAGTA-3'), human Rab5b (5'-AAGACAGCTATGAACGTGAAT-3'), and human Rab5c (5'-AAAGACTGCAATGAACGTGAA-3'). Equal amounts of sense and antisense RNA oligonucleotides were mixed and annealed according to the manufacturer's protocol to form RNA duplexes before transfection. Cells were seeded at a density of 250000 cells/35 mm dish. The transfection of siRNA (10 nM final concentration) was performed using HiPerFect transfection reagent (QIAGEN). Twelve microliters of HiPerFect transfection reagent (QIAGEN) and $1.2 \mu \mathrm{l}$ of $20 \mu \mathrm{M}$ siRNA of each duplex were added to $100 \mu \mathrm{l}$ of Opti-MEM medium (GIBCO) and incubated at room temperature for $10 \mathrm{~min}$. The transfection mixture was then added to each culture dish containing $2.3 \mathrm{ml}$ fresh MEM with Earle's salt supplemented with 10\% fetal calf serum without antibiotics. Control cells were treated equally but with no Rab siRNA duplexes. All experiments were carried out $72 \mathrm{~h}$ later. The efficiency of siRNA silencing was assessed by immunoblotting using a purified rabbit polyclonal anti-Rab5a antibody (Santa Cruz), a

Table 1

Amino acid sequences of the C-terminal domain of native and truncated $\mathrm{Y}_{1}$ receptors. The point mutation ( $\mathrm{Y} / \mathrm{F}$ ) in the $\mathrm{YXX} \Phi$ domain (underlined) is indicated in italics. Amino acids belonging in the 7th transmembrane domain are shadowed in gray.

\begin{tabular}{|c|c|}
\hline PIFY GFLNKNFQRD LQFFFNFCDF RSRDDDYETI AMSTMHTDVS KTSLKQASPV AFKKINNNDD NEKI & $\mathrm{Y}_{1} \mathrm{WT}$ \\
\hline PIFY GFLNKNFQRD LQFFFNFCDF RSRDDD $\underline{\overline{Y E T I} A M}$ & $\mathrm{Y}_{1} \Delta 32$ \\
\hline PIFY GFLNKNFQRD LQFFFNFCDF RS & $\mathrm{Y}_{1} \Delta 42$ \\
\hline PIFY GFLNKNFQRD LQFFFNFCDF RSRDDDFETI GMSTMHTDVS KTSLKQASPV AFKKINNNDD NEKI & $\mathrm{Y}_{1} \mathrm{Y} 347 \mathrm{~F}$ \\
\hline PIFY GFLNKNFQRD LQFFFNFCDF RSRDDD $\overline{\overline{F E T I}}$ AM & $\mathrm{Y}_{1} \Delta 32 \mathrm{Y} 347 \mathrm{~F}$ \\
\hline PIFY GFLNKNFQRD LQFFFNFCDF RSRDDD $\underline{A E T A}$ AM & $\begin{array}{l}Y_{1} \Delta 32 \\
Y 347 A, I 350 A\end{array}$ \\
\hline
\end{tabular}


purified rabbit polyclonal anti-Rab5b antibody (Santa Cruz), and a purified goat polyclonal anti-Rab5c antibody (Santa Cruz).

\section{3. cAMP measurements}

Functional NPY receptor coupling to adenylyl cyclase was assessed by measuring the dose-dependent inhibitory effects of NPY on forskolin-stimulated cAMP accumulation by radioimmunoassay, as previously described [1]. To study desensitization of the inhibition of adenylyl cyclase, cells were preincubated for $10 \mathrm{~min}$ at $37^{\circ} \mathrm{C}$ without or with $100 \mathrm{nM}$ NPY. After rinsing, cells were assayed using different concentrations of NPY for inhibition of forskolin-stimulated cAMP accumulation.

\subsection{Western blot analysis}

As previously described [1], near confluent HEK293 cultures expressing different NPY receptors were washed with cold PBS and incubated after sonication with lysis buffer at $4{ }^{\circ} \mathrm{C}$ for $1 \mathrm{~h}$. Cell lysates were solubilized in Laemmli's buffer, resolved by SDS-PAGE and transferred to PVDF membranes (Amersham). After blocking at (1 h at room temperature, I-Block Reagent; Tropix), membranes were incubated overnight at $4{ }^{\circ} \mathrm{C}$ with either a mouse monoclonal antiGFP antibody (Roche; $1 / 1000$ dilution) or a rabbit polyclonal antiRab5a antibody (Santa Cruz; 1/1000 dilution) or a rabbit polyclonal anti-Rab5b antibody (Santa Cruz; $1 / 1000$ dilution) or a goat polyclonal anti-Rab5c antibody (Santa Cruz; 1/300 dilution). Membranes were then incubated at room temperature for $1 \mathrm{~h}$ with either an anti-mouse IgG (for GFP) coupled to HRP (1/50 000) or an antirabbit IgG (for Rab5a and Rab5b) coupled to HRP (1/20 000) or an anti-goat IgG (for Rab5c) coupled to HRP (1/5000). Specific staining was revealed using an ECL plus kit (Amersham). Blots from at least 3 different experiments were analyzed by densitometry.

\subsection{Fluorescence measurements of agonist-induced internalization of $Y_{1}$ receptors}

Measurements of the pH-dependent variation of EGFP fluorescence (reflecting receptor internalization and trafficking to acidic endosomal compartments; [1]) were performed as described previously [1]. Briefly, transfected HEK293 cells were grown on $35 \mathrm{~mm}$ plastic dishes for 2 days, washed with PBS, harvested after incubation in a PBS-EDTA $5 \mathrm{mM}$ buffer, pH 7.4, and resuspended in Krebs-Ringer buffer. Measurements from cell suspensions were done using a spectrofluorimeter (Fluorolog, SPEX) equipped with a 450 W Xe lamp, a double grating excitation monochromator, and a single grating emission monochromator. Slits were set to $4 \mathrm{~nm}$ yielding bandwidths of $7.2 \mathrm{~nm}$ at excitation $(470 \mathrm{~nm})$ and $14.4 \mathrm{~nm}$ at emission $(510 \mathrm{~nm})$. Data were acquired with a photon counting photomultiplier (linear up to $10^{7}$ counts $\left./ \mathrm{s}\right)$. Suspensions $\left(10^{6} \mathrm{cells} / \mathrm{ml}\right)$ were placed in a $1 \mathrm{ml}$ cuvette with magnetic stirring at $37{ }^{\circ} \mathrm{C}$ and recordings were made every $1 \mathrm{~s}$.

\subsection{Internalization of $Y_{1}$ receptors measured using anti-GFP antibodies}

Transfected cells were suspended $\left(10^{6}\right.$ cells $\left./ \mathrm{ml}\right)$ in $12 \mathrm{ml}$ of HEPES-BSA. The cell suspension was separated into $2 \times 50 \mathrm{ml}$ Falcon tubes, stirred with a magnetic stirrer and incubated at $4{ }^{\circ} \mathrm{C}$. At different times thereafter over $30 \mathrm{~min}, 1 \mathrm{ml}$ of the cell suspensions was collected from both tubes and transferred to a $1.5 \mathrm{ml}$ tube containing $10 \mu \mathrm{l}$ sodium azide (10\%) chilled in ice. After this first incubation period at $4{ }^{\circ} \mathrm{C}$, cells were rapidly transferred at $37{ }^{\circ} \mathrm{C}$ and again over a period of $30 \mathrm{~min}, 1 \mathrm{ml}$ of the cell suspensions was collected and treated as above. At the end of the two incubation periods, cells were pelleted by centrifugation ( $3 \mathrm{~min}, 2000 \mathrm{~g}$ ) at $4{ }^{\circ} \mathrm{C}$ and resuspended in $1 \mathrm{ml}$ ice-cold PBS-1\% BSA on ice for
$15 \mathrm{~min}$. Cells were labeled using a monoclonal mouse anti-GFP antibody (Roche; $1 / 200$ dilution) for $30 \mathrm{~min}$ on ice, washed 3 times with $1 \mathrm{ml}$ of ice-cold PBS-1\% BSA; a secondary labeling uses a Rphycoerythrin-conjugated AffiniPure $\mathrm{F}(\mathrm{ab}) 2$ fragment goat anti-mouse IgG (Immunotech; 1/200). Samples were washed 2 times in $1 \mathrm{ml}$ of PBS, fixed for $5 \mathrm{~min}$ in ice-cold PBS-4\% paraformaldehyde and finally resuspended in $0.2 \mathrm{ml}$ of ice-cold PBS, and stored overnight. Rphycoerythrin staining of GFP-positive cells (in general 10000 cells per sample were recorded) was quantified by flow cytometry using FACSCalibur flow cytometer equipped with Cellquest software (BectonDickinson). EGFP was excited using a $488 \mathrm{~nm}$ argon ion laser and detected with $530 \pm 30-\mathrm{nm}$ band pass filter. R-phycoerythrin (PE) was excited at $488 \mathrm{~nm}$ and detected with a $585 \pm 42-\mathrm{nm}$ band pass filter. After subtraction of non-specific staining measured on non-transfected cells, the proportion of GFP-tagged receptors at the cell surface was directly correlated to the ratio of the PE fluorescence intensity at $37^{\circ} \mathrm{C}$ to that at $4{ }^{\circ} \mathrm{C}$.

\subsection{Fluorescence confocal microscopy}

For endosome/EGFP-NPY receptor co-localization, cells were split and grown for 2 days in 24-well plates on $12 \mathrm{~mm}$ glass coverslips coated with rat type I collagen. Cells were washed twice with KrebsRinger buffer (in mM: $136 \mathrm{NaCl}, 1.8 \mathrm{KCl}, 1.2 \mathrm{KH}_{2} \mathrm{PO}_{4}, 1.2 \mathrm{MgSO}_{4}, 5$ $\mathrm{NaHCO}_{3}, 1.2 \mathrm{CaCl}_{2}, 0.21$ EGTA, 5.5 glucose, 20 HEPES, $1 \mathrm{mg} / \mathrm{ml} \mathrm{BSA}, \mathrm{pH}$ 7.4) and then starved by $1 \mathrm{~h}$ incubation in serum-free medium. Cells were then incubated at $37^{\circ} \mathrm{C}$ for periods ranging from 0 to $60 \mathrm{~min}$ in Krebs-Ringer buffer containing $20 \mu \mathrm{g} / \mathrm{ml}$ transferrin-Texas Red in the absence of NPY. Transferrin uptake was stopped by placing cells on ice and washing immediately with ice-cold Krebs-Ringer buffer. Cells were then fixed in $4 \%$ paraformaldehyde-Krebs-Ringer buffer (without glucose and BSA) for $15 \mathrm{~min}$ at $4{ }^{\circ} \mathrm{C}$ and then incubated for $15 \mathrm{~min}$ in $50 \mathrm{mM} \mathrm{NH}_{4} \mathrm{Cl}$ to quench any remaining paraformaldehyde and remove cellular autofluorescence. Coverslips were mounted onto slides using an anti-fading agent (Mowiol; Calbiochem). Cells were observed with an inverted microscope (Nikon Eclipse TE300) and a laser scanning confocal imaging system (Bio-Rad MRC1024) using a Plan Apo $60 \times 1.20$ n.a. water immersion objective (Nikon). Electronic zoom was 2, the pinhole was 2.7 and the pixel size was $0.275 \mu \mathrm{m}$. Excitation was from a $15 \mathrm{~mW} \mathrm{Kr} / \mathrm{Ar}$ laser at $10 \%$ power. Each stack of 2-D images was acquired sequentially in the green channel (PMT2, excitation $488 \mathrm{~nm}$, emission $522 \mathrm{~nm}$ ) and in the red channel (PMT1, excitation $568 \mathrm{~nm}$, emission $605 \mathrm{~nm})$, before stepping $(0.3 \mu \mathrm{m})$ the objective in the Z-axis.

\subsection{Image analysis}

For fluorescence intensities and co-localization analysis, confocal stack images were first deconvolved using 3-D blind deconvolution (AutoDeblur software, AutoQuant Imaging) and then treated with ImageJ software. Briefly, a scatter plot was created which is a statistical representation that shows colour and intensity distributions of pixels in a pair of images (X-axis, red and Y-axis, green). After selecting an area in the plot having high intensity fluorescence in both channels, a new black and white image of the selected cell was generated, which represents the cellular localization of these high intensity pixels. To allow analysis of statistical differences between $Y_{1}$ and $Y_{1} \Delta 32$-transfected cells, the degree of co-localization was also calculated using Pearson's coefficient. This describes the degree of overlap between image pairs according to the following formula: $\mathrm{R}_{\mathrm{r}}=\sum\left(\mathrm{S}_{1 \mathrm{i}}-\mathrm{S}_{1 \text { aver }}\right) \cdot\left(\mathrm{S}_{2 \mathrm{i}}-\mathrm{S}_{2 \mathrm{aver}}\right) / \sqrt{ } \sum\left(\mathrm{S}_{1 \mathrm{i}}-\mathrm{S}_{1 \text { aver }}\right)^{2} \cdot\left(\mathrm{S}_{2 \mathrm{i}}-\mathrm{S}_{2 \mathrm{aver}}\right)^{2}$, where $S_{1}$ and $S_{2}$ are the pixel intensities in the first and second images respectively and $S_{1 \text { aver }}$ and $S_{2 a v e r}$ are the average intensities of first and second images. 


\subsection{Peptides and chemicals}

Human NPY was from Neosystem; all other chemicals were from Sigma. BIBP3226 was kindly supplied by Dr. H. Doods (Boehringer Ingelheim, Biberach, Germany).

\section{Results}

\subsection{Expression and functional coupling of $Y_{1} \Delta 32$ receptors}

Expression of EGFP-tagged $Y_{1}$ and $Y_{1} \Delta 32$ receptors in HEK293 cells was confirmed by the characteristic excitation and emission spectra of EGFP (not shown). On Western blots probed with anti-GFP antibodies, $Y_{1} \Delta 32$ receptors were smaller than full-length $Y_{1}$ receptors, consistent with the C-terminal deletion of amino acids (Fig. 1A). On confocal micrographs, in the absence of agonist, $Y_{1}$ receptors are strongly and uniformly expressed at the plasma membrane (Fig. 1B,a), while in contrast, $Y_{1} \Delta 32$ receptors are localized mostly in punctate intracellular structures with some expression at the plasma membrane (Fig. 1B,b). Functional activity of transfected receptors was assessed by determining $\mathrm{G}_{\mathrm{i} / \mathrm{o}}$-dependent inhibition of forskolin-stimulated adenylyl cyclase. On both $\mathrm{Y}_{1}$ and $\mathrm{Y}_{1} \Delta 32$ receptors, NPY application inhibited cAMP accumulation in a concentration-dependent manner (Fig. 1C). In addition, BIBP3226 ( $1 \mu \mathrm{M})$, a specific $Y_{1}$ antagonist, induces a rightward shift in the NPY dose-response curve with no change in the maximal effect (data not shown) for both $Y_{1}$ and $Y_{1} \Delta 32$ receptors.

\subsection{Agonist-independent internalization of $Y_{1} \Delta 32$ receptors}

A quantitative FACS assay was set up to determine whether the intracellular localization of $\mathrm{Y}_{1} \Delta 32$ receptors (Fig. 1B) might reflect internalized receptors due to tonic internalization in the absence of agonist, as recently suggested [13]. Cells expressing $\mathrm{Y}_{1} \Delta 32$ receptors were incubated at $4{ }^{\circ} \mathrm{C}$, a condition which fully inhibits $Y_{1}$ receptor internalization due to the temperature dependence of the internalization process [21]. After $30 \mathrm{~min}$ at $4{ }^{\circ} \mathrm{C}$, cells were placed at $37^{\circ} \mathrm{C}$ and at various time points covering a $30 \mathrm{~min}$ period, cells were fixed and stained with an anti-GFP antibody followed by a phycoerythrinconjugated goat anti-mouse IgG. Quantification of $\mathrm{Y}_{1} \Delta 32$ receptors present at the cell surface was done by measuring phycoerythrin staining of GFP-positive cells. Transfected $Y_{1}$ cells were treated in a similar manner.

In Fig. 2, representative examples of FACS data for $\mathrm{Y}_{1}$ (Fig. 2A,B) and $\mathrm{Y}_{1} \Delta 32$ (Fig. 2C,D) receptors at $4{ }^{\circ} \mathrm{C}$ and $37^{\circ} \mathrm{C}$ are shown. Incubation of transfected cells at $4{ }^{\circ} \mathrm{C}$ results in a stable steady-state distribution of both $Y_{1}$ and $Y_{1} \Delta 32$ receptors at the plasma membrane (Fig. 2E). Within $10 \mathrm{~min}$ after transfer to $37^{\circ} \mathrm{C}$, cell surface amounts of $\mathrm{Y}_{1} \Delta 32$ receptors decreased dramatically (Fig. 2D,E), unlike for $\mathrm{Y}_{1}$ receptors which remained at the cell surface (Fig. 2B,E). When this experiment was repeated in the presence of a submaximal concentration of the selective $Y_{1}$ receptor antagonist BIBP3226 $(10 \mu \mathrm{M})$, the decrease in the amounts of cell surface $Y_{1} \Delta 32$ receptors was again observed when cells were transferred from $4{ }^{\circ} \mathrm{C}$ to $37^{\circ} \mathrm{C}$ (Fig. 2F). This indicates that $\mathrm{Y}_{1} \Delta 32$ receptors undergo constitutive internalization at $37^{\circ} \mathrm{C}$ that does not require receptor signaling.

\section{3. $Y_{1} \Delta 32$ receptors constitutively internalize via clathrin-coated pits}

To determine whether, at $37^{\circ} \mathrm{C}$ and in the absence of agonist, $\mathrm{Y}_{1} \Delta 32$ receptors are sequestered into an endosomal compartment, their subcellular localization was visualized using EGFP signals together with that of transferrin-Texas Red, a marker of clathrinassociated internalization and recycling pathways. In the absence of NPY, wild-type (WT) $Y_{1}$ staining was essentially associated with cell membranes, whereas in contrast, $\mathrm{Y}_{1} \Delta 32$ receptors were detected both at the cell membrane and in distinct patches in the cytosol (Fig. 3A). For both transfected cell types, transferrin-Texas Red staining was in the cytosol, with co-localized cytoplasmic signals being observed only for $Y_{1} \Delta 32$ receptors (yellow pixels, Fig. 3A overlay). The cellular colocalization of transferrin-Texas Red and $Y_{1} \Delta 32$ receptors was analyzed and quantified by two methods. Firstly, high intensity yellow pixels were extracted (yellow circles in Fig. 3B) from a 2colour scatter plot (representing the intensity distribution of pixels in a pair of images: green for $Y_{1}$ receptors, red for transferrin) to form a new image. The corresponding image (Fig. 3B, white dots) indicates that these high intensity pixels, reflecting co-localized transferrin and EGFP signals, are located both at the plasma membrane and in the cytosol of $\mathrm{Y}_{1} \Delta 32$-expressing cells, unlike $\mathrm{Y}_{1}$-transfected cells, where
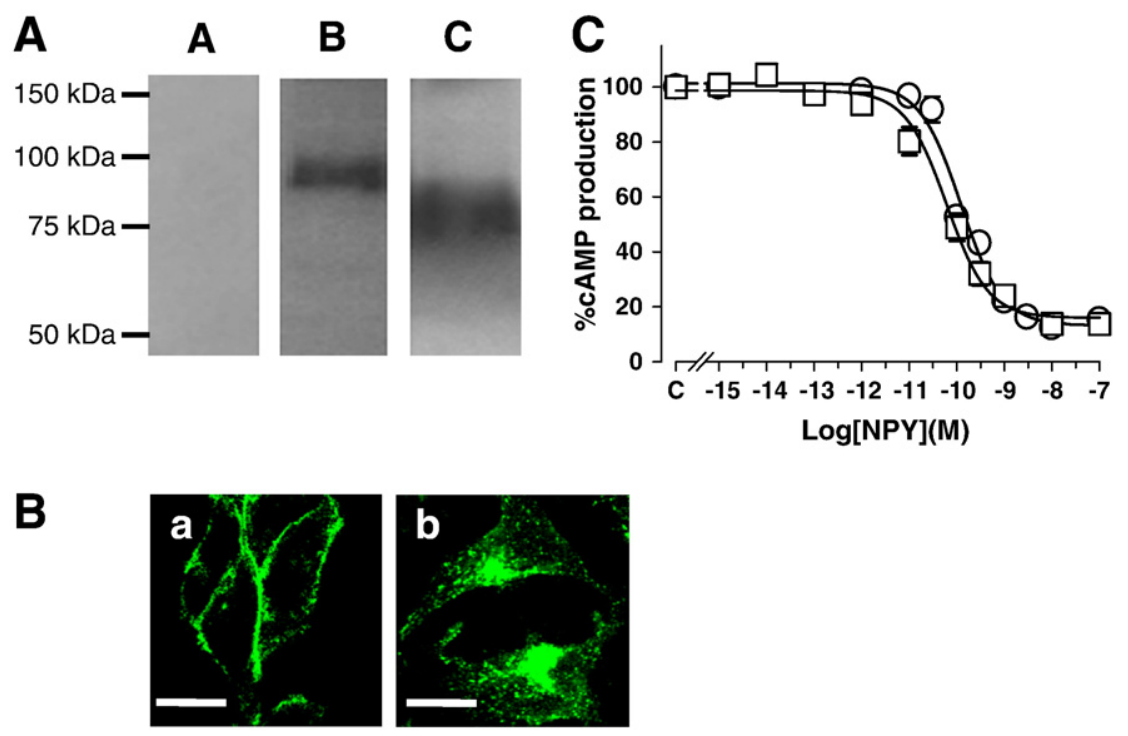

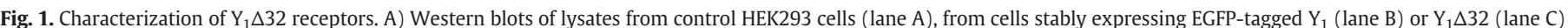

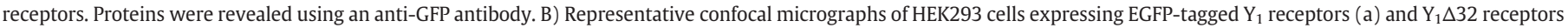

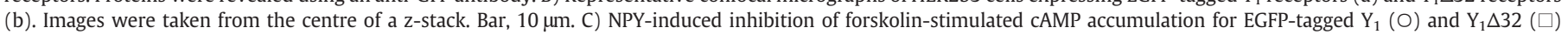
receptors. Data represent the mean \pm sem of 10-11 independent experiments, each performed in duplicate. 
A

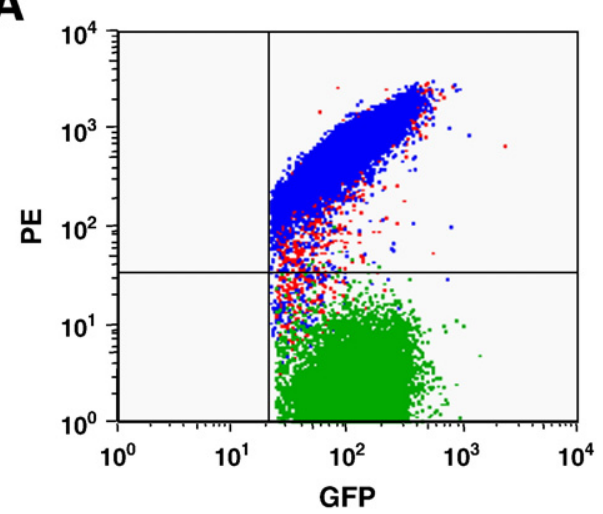

C

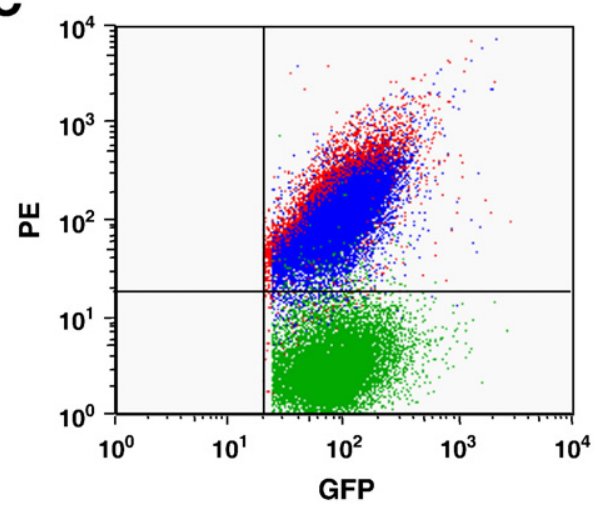

$\mathbf{E}$

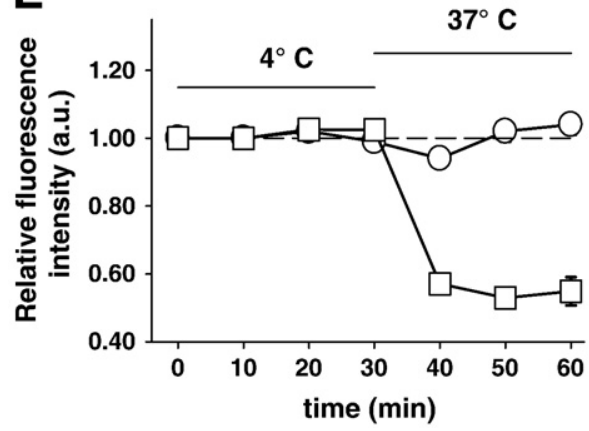

B

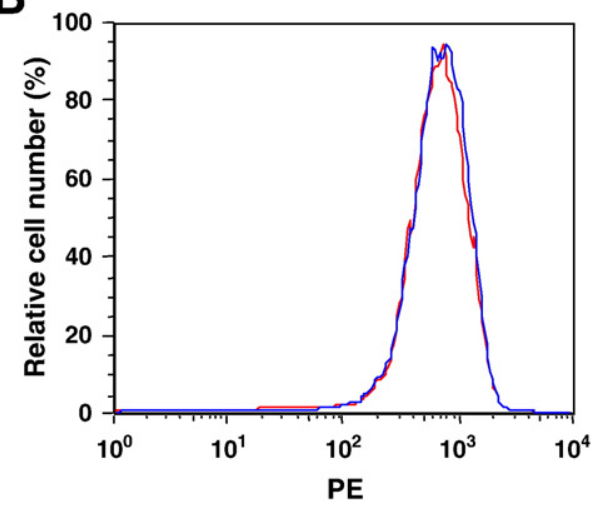

D

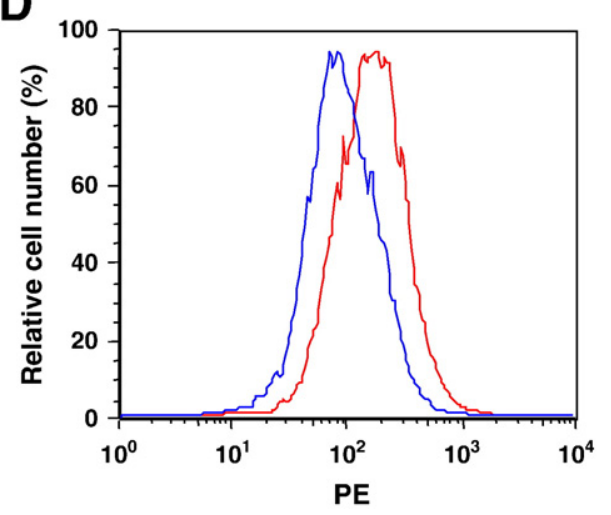

$\mathbf{F}$

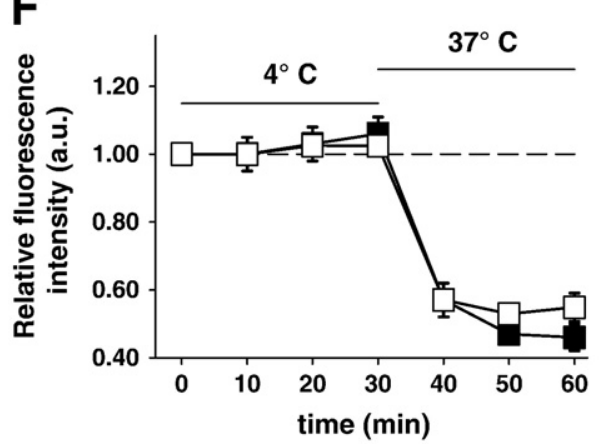

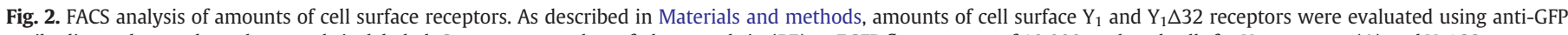

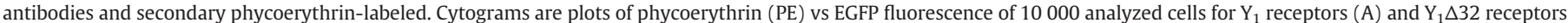

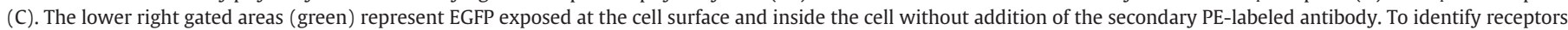

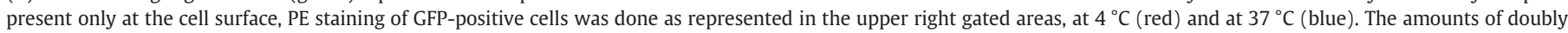

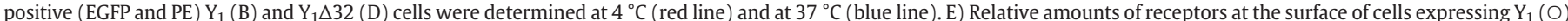

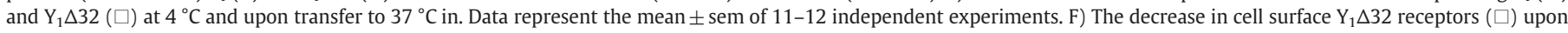

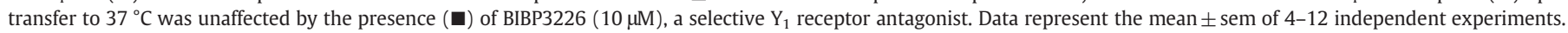

these pixels are essentially located at the cell membrane. Secondly, we quantified co-localization using Pearson's coefficient analysis, which calculates, as a measure of co-localization, the degree of overlap between paired images. There was a significantly higher Pearson's coefficient for pair-wise comparison of images from transferrin with $Y_{1} \Delta 32$ receptors than for transferrin with $Y_{1}$ receptors (Fig. 3B).

To further characterize the mechanisms implicated in the internalization cells were treated with compounds blocking different pathways of GPCR internalization. Sucrose, a blocker of clathrinmediated internalization $[22,23]$, was used in the FACS assay described above. At $400 \mathrm{mM}$, sucrose completely blocked the decrease in cell surface $Y_{1} \Delta 32$ receptors observed upon transfer of cells from $4{ }^{\circ} \mathrm{C}$ to $37^{\circ} \mathrm{C}$ (Fig. 3C). In contrast, filipin, a cholesterol-binding compound that has been shown to disassemble lipid rafts by dispersing cholesterol in the membrane and which does not inhibit clathrin-mediated endocytosis [24,25], had no effect on constitutive internalization (Fig. 3D), indicating that the endocytosis of $Y_{1} \Delta 32$ receptors was not dependent on cholesterol-rich caveolae. As a whole, these data support that non-activated $Y_{1} \Delta 32$ receptors are constitutively internalized via a pathway involving clathrin-coated pits.

\subsection{Dominant negative Rab5a decreases constitutive internalization of $Y_{1} \Delta 32$ receptors}

In the early endocytic pathway, Rab5a is very likely one of the trafficking regulators implicated in clathrin-coated vesicle endocytosis 
A
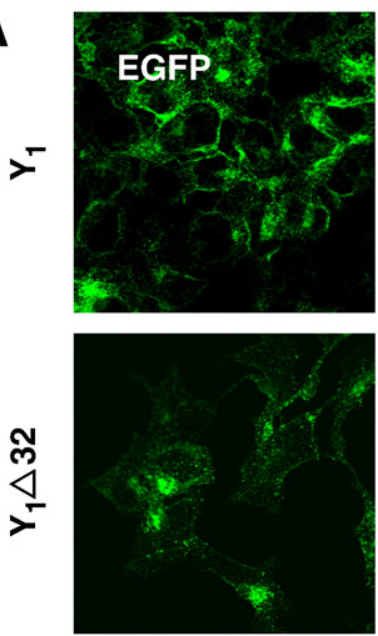

B
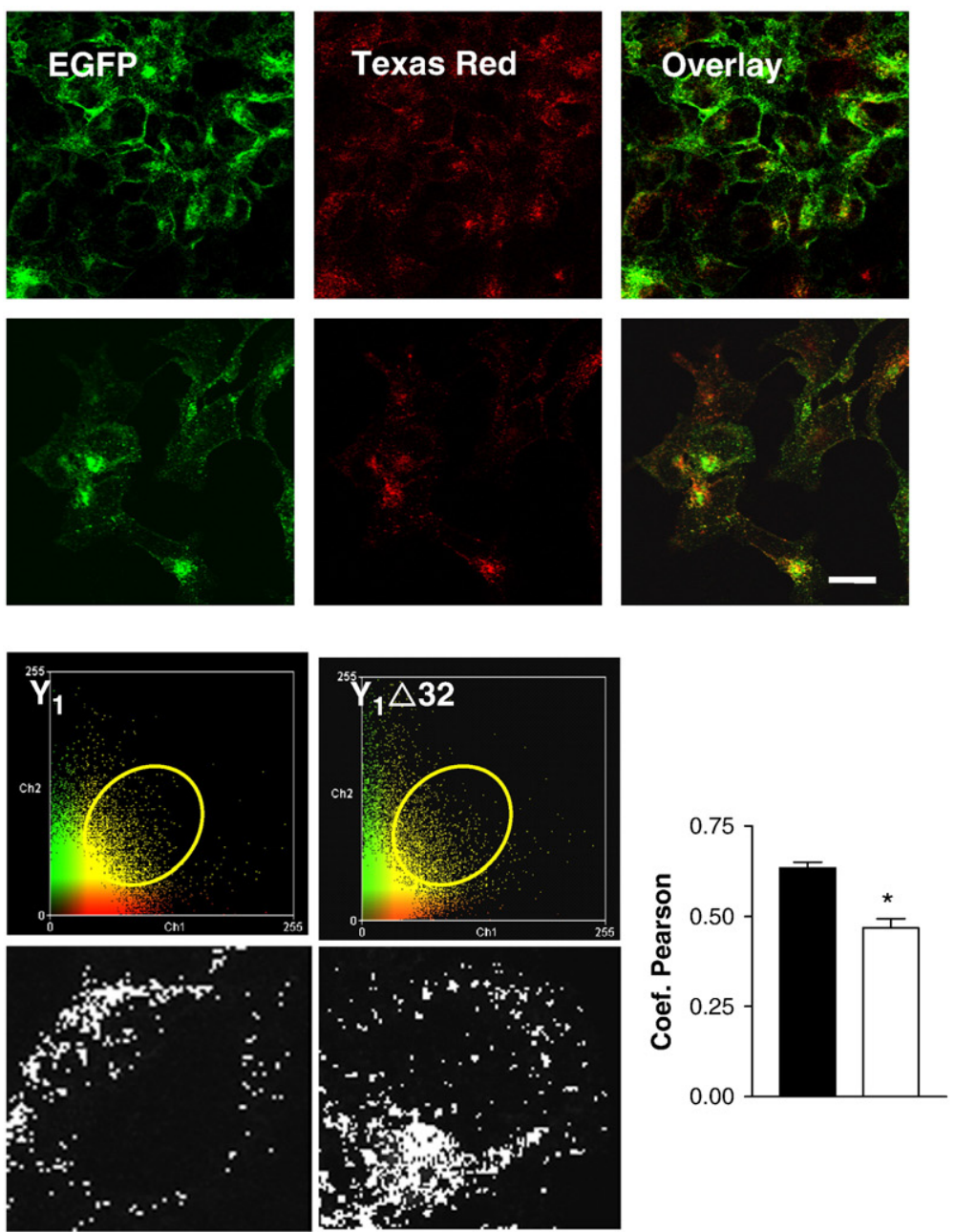

C

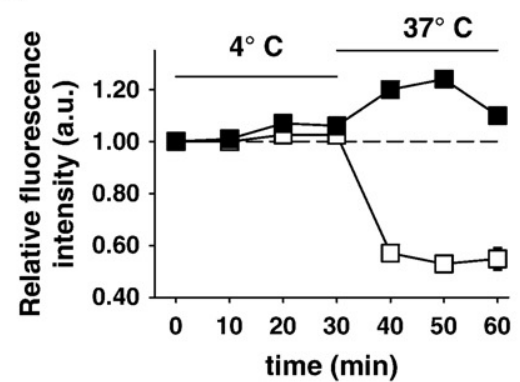

D

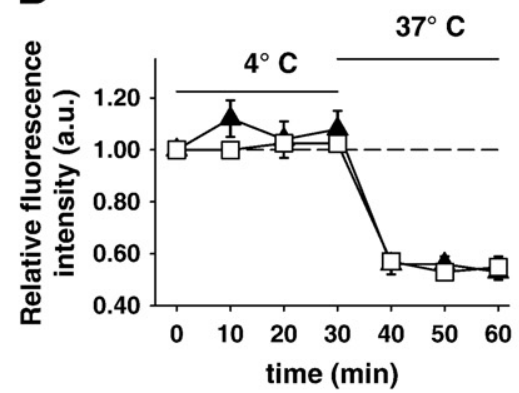

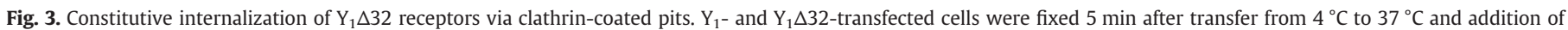

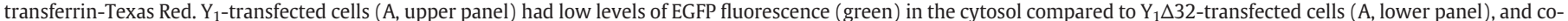

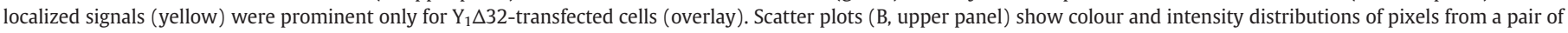

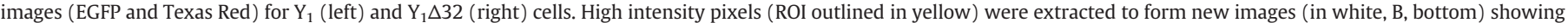

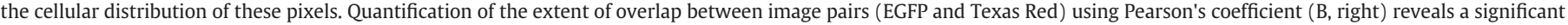

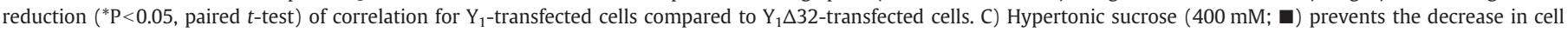

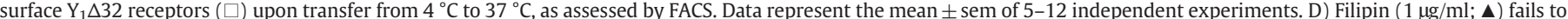

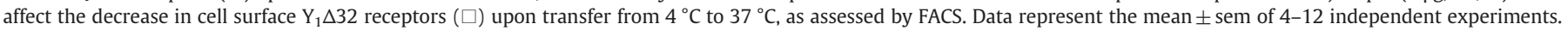

from the plasma membrane to early endosomes. If so, constitutive internalization of $Y_{1} \Delta 32$ receptors might well be affected in cells coexpressing a dominant negative form, Rab5aS34N. Thus, cells stably expressing $\mathrm{Y}_{1} \Delta 32$ receptors were transiently co-transfected with Rab5aS34N tagged with mRFP1, a red fluorescent protein [26].

Western blots probed with Rab5a antibody revealed endogenous Rab5a $(\approx 25 \mathrm{kDa})$ in $\mathrm{Y}_{1} \Delta 32$ cells and mRFP1-Rab5aS34N $(\approx 55 \mathrm{kDa})$, compatible with the expected sizes of Rab5a and mRFP1 $(\approx 30 \mathrm{kDa})$ in co-transfected cells (Fig. 4A). In the absence of agonist, Rab5aS34N was localized close to the plasma membrane of $Y_{1} \Delta 32$-expressing cells and prominently concentrated in perinuclear structures. Strikingly, coexpression of Rab5aS34N caused retention of $Y_{1} \Delta 32$ receptors at the cell surface with less EGFP signals in the cytoplasm (Fig. 4B) compared to cells expressing only $\mathrm{Y}_{1} \Delta 32$ receptors (Fig. $1 \mathrm{~B}, \mathrm{~b}$ ). Cellular co-localization 
A

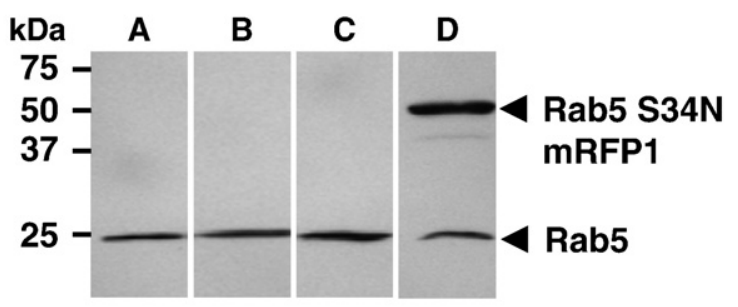

C

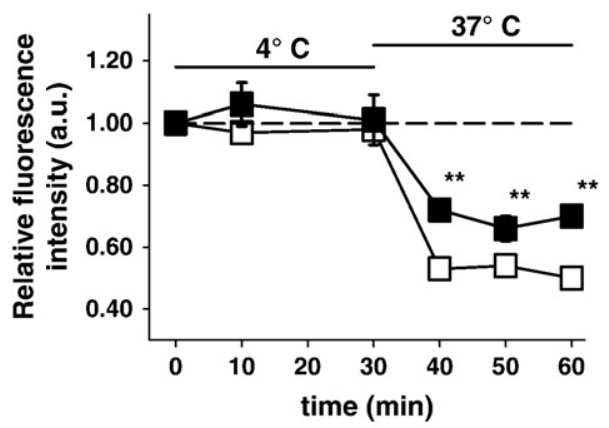

B
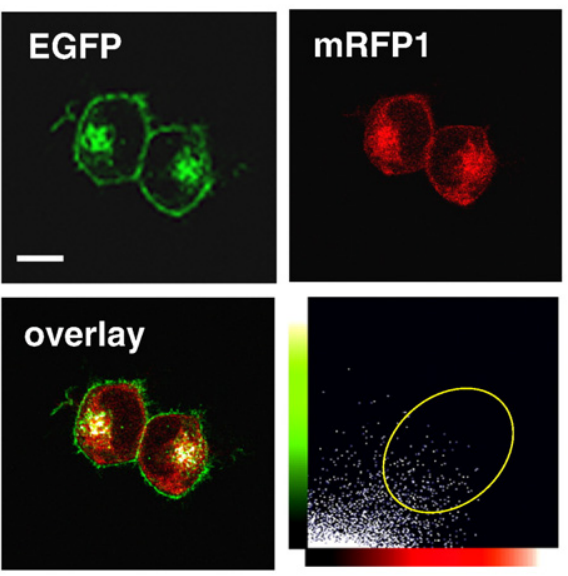

D

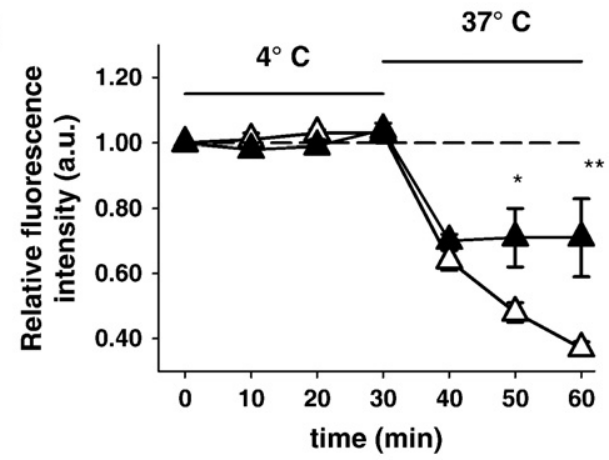

E

IB

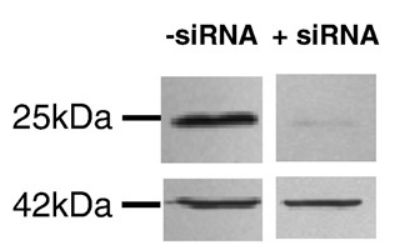

Rab5B

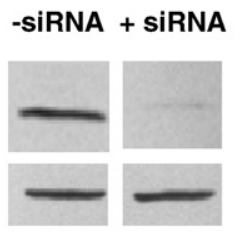

Rab5C

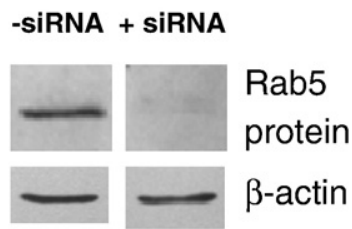

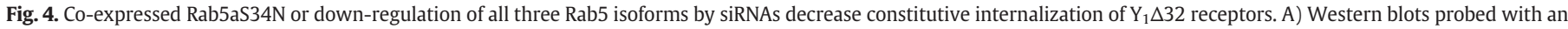

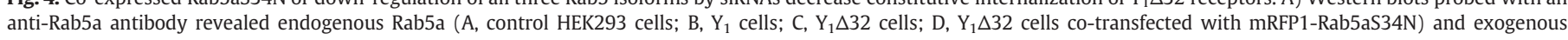

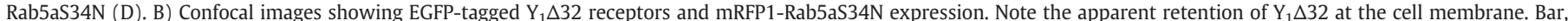

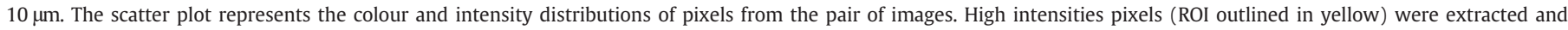

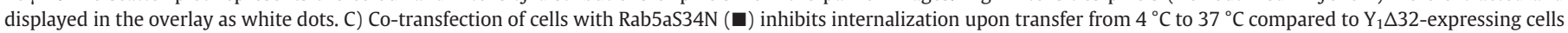

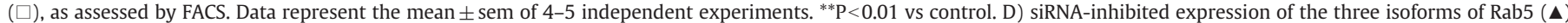

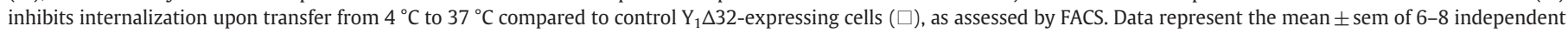

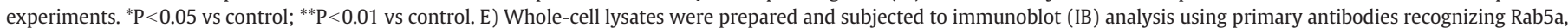

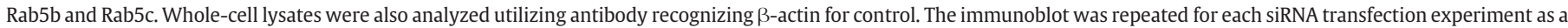

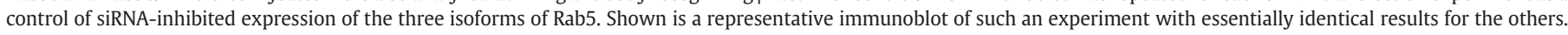

of EGFP and mRFP1 signals was then evaluated by image analysis, as above. High intensity pixels were extracted from the 2-colour scatter plot (Fig. 4B, yellow circle, lower right panel) and represented as white dots on the overlay image (Fig. 4B, lower left panel). As seen in the scatter plot, very few pixels exhibit high intensities in both green and red channels, indicating a low degree of co-localization for Rab5aS34N and $\mathrm{Y}_{1} \Delta 32$ receptors, essentially limited to punctate perinuclear structures. In addition, upon transfer from $4{ }^{\circ} \mathrm{C}$ to $37^{\circ} \mathrm{C}$ in the FACS assay, $Y_{1} \Delta 32$ cells co-expressing Rab5aS34N, show significant reduction $(\mathrm{P}<0.01$; one-way ANOVA test) in internalization compared to cells expressing only $Y_{1} \Delta 32$ receptors (Fig. $4 C$ ). Together, these data are consistent with constitutive internalization of $Y_{1} \Delta 32$ receptors occurring via a trafficking pathway involving Rab5.

\subsection{RNA interference of Rab5 isoforms decrease constitutive internalization of $Y_{1} \Delta 32$ receptors}

Rab5 has three structurally related isoforms (Rab5a, Rab5b, and Rab5c). siRNA down-regulation of a single Rab5 isoform targeted to Rab5a had no effect on the constitutive endocytosis of $Y_{1} \Delta 32$ receptors (data not shown). Simultaneous depletions of the three Rab5 isoforms by using small interfering RNAs (siRNA) specific of each of them were performed. The extent of each Rab5 silencing was quantified by Western blotting. In our experimental conditions, Western blotting analysis showed that RNA interference against the three isoforms of Rab5 effectively resulted in an appropriate depletion of each isoform by more than $90 \%$ as compared to negative control siRNA-transfected cells 
A

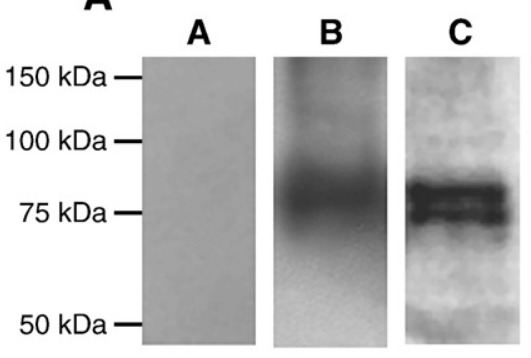

C

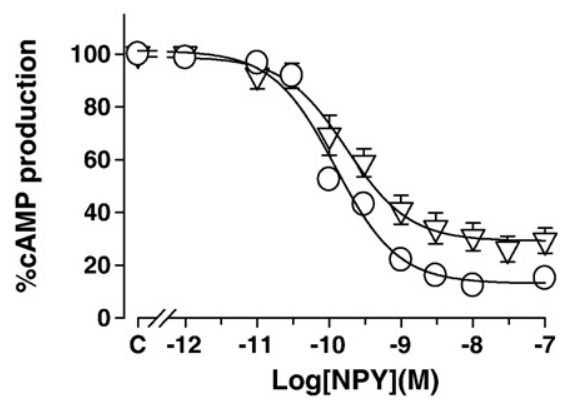

B

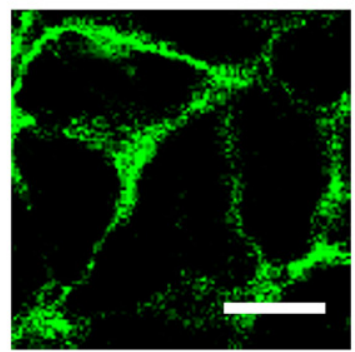

D

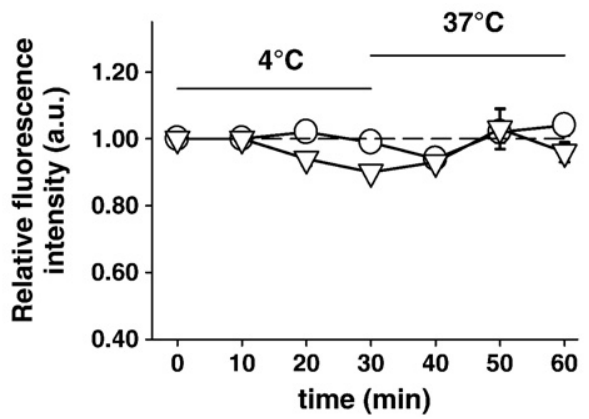

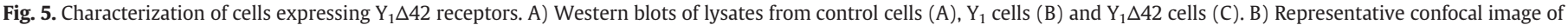

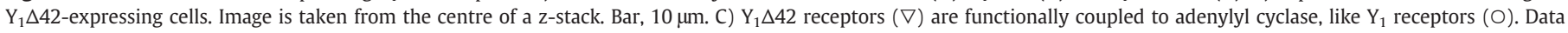

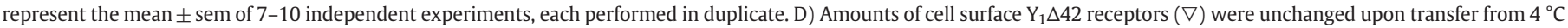
to $37^{\circ} \mathrm{C}$, as for $\mathrm{Y}_{1}$ receptors $(\mathrm{O})$, as assessed by FACS. Data represent the mean \pm sem of 4-11 independent experiments.

(Fig. 4E). By utilizing this RNA interference-mediated depletion of the three Rab5 isoforms, we examined whether these GTPases are required for $Y_{1} \Delta 32$ constitutive internalization. Upon transfer from $4{ }^{\circ} \mathrm{C}$ to $37^{\circ} \mathrm{C}$, there was a significant impairment but not full abolition $(\mathrm{P}<0.01$; oneway ANOVA test) in internalization of $\mathrm{Y}_{1} \Delta 32$ receptors (Fig. 4D). These data provide additional evidence that constitutive internalization of $\mathrm{Y}_{1} \Delta 32$ receptors occurs via a trafficking pathway involving at least in part the three Rab5 isoforms.

\section{6. $Y_{1} \Delta 42$ receptors are not constitutively internalized}

In an effort to identify the motifs responsible for constitutive internalization of $Y_{1} \Delta 32$ receptors, a $Y_{1}$ deletion mutant having a further truncation of $10 \mathrm{C}$-terminal amino acids was used $\left(\mathrm{Y}_{1} \Delta 42\right)$. On Western blots, EGFP-tagged $Y_{1} \Delta 42$ receptors had a lower molecular weight compared to $W T Y_{1}$ receptors (Fig. 5A). $Y_{1} \Delta 42$ receptors are exclusively and uniformly expressed at the plasma membrane (Fig. 5B). They are functional as forskolin-stimulated cAMP accumulation is inhibited in a concentration-dependent manner. In our FACS assay, at $4{ }^{\circ} \mathrm{C}$ and in the absence of agonist, both $Y_{1}$ and $Y_{1} \Delta 42$ receptors are stably expressed at the plasma membrane (Fig. 5D). When cells are transferred to $37^{\circ} \mathrm{C}$, the amounts of cell surface receptors remain constant, indicating that $\mathrm{Y}_{1} \Delta 42$ receptors do not undergo constitutive internalization like $Y_{1}$ receptors (Fig. 5D). This observation strongly suggests that the signal motif directing constitutive internalization is absent in $Y_{1} \Delta 42$ receptors.

\subsection{A tyrosine-based motif drives constitutive internalization of the $Y_{1} \Delta 32$ receptor}

Analysis of the $10 \mathrm{C}$-terminal amino acids deleted in $\mathrm{Y}_{1} \Delta 42$ receptors compared to $Y_{1} \Delta 32$ receptors reveals the presence of a YETI sequence (amino acids 347-350). This sequence fits well with the YXX $\Phi$ consensus motif that has been implicated in internalization of membrane proteins via a direct interaction with the AP-2 adaptor complex [19,27-29]. This may well explain the constitutive internalization observed for $Y_{1} \Delta 32$ but not $Y_{1} \Delta 42$ receptors. We tested this hypothesis by constructing $Y_{1} \Delta 32$ receptors having a point mutation where Tyr347 (in the YETI motif) was replaced by Phe $\left(\mathrm{Y}_{1} \Delta 32^{\mathrm{Y} 347 \mathrm{~F}}\right)$. The mutant was stably expressed in HEK293 cells, and on Western blots, $\mathrm{Y}_{1} \Delta 32^{\mathrm{Y} 347 \mathrm{~F}}$ receptors had a slightly lower molecular weight compared to WT $Y_{1}$ receptors (Fig. $6 \mathrm{~A}$ ). On confocal micrographs, like $\mathrm{Y}_{1} \Delta 32$ receptors, $\mathrm{Y}_{1} \Delta 32^{\mathrm{Y} 347 \mathrm{~F}}$ receptors are found both at the plasma membrane and in intracellular structures (Fig. 6B, upper panel). Like WT $Y_{1}$ and $Y_{1} \Delta 32$ receptors, $Y_{1} \Delta 32^{\mathrm{Y} 347 \mathrm{~F}}$ receptors are functionally coupled to adenylyl cyclase (Fig. 6C). Interestingly, in our FACS assay, we observe a significant reduction (from $54 \%$ to $40 \%$; $\mathrm{P}<0.01$; oneway ANOVA test) in constitutive internalization of $\mathrm{Y}_{1} \Delta 32^{\mathrm{Y} 347 \mathrm{~F}}$ receptors compared to $\mathrm{Y}_{1} \Delta 32$ receptors upon transfer from $4{ }^{\circ} \mathrm{C}$ to $37^{\circ} \mathrm{C}$ (Fig. 6D). This is consistent with Tyr347 in the YETI motif playing a role in the constitutive internalization of $Y_{1} \Delta 32$ receptors. In order to investigate the importance of the hydrophobic isoleucine, a double mutant was constructed in which the tyrosine and isoleucine in position 347 and 350 respectively, are replaced by an alanine. The stably expressed $\mathrm{Y}_{1} \Delta 32^{\mathrm{Y} 347 \mathrm{~A} / 1350 \mathrm{~A}}$ receptors have, like the $\mathrm{Y}_{1} \Delta 32^{\mathrm{Y} 347 \mathrm{~F}}$ receptors the same lower molecular weight as compared to the WT $Y_{1}$ receptors (Fig. 6A). In confocal micrographs the double mutated $\mathrm{Y}_{1} \Delta 32$ receptor is found both at the membrane and in intracellular structures (Fig. 6B, bottom figure). It is also negatively coupled to adenylyl cyclase (Fig. 6C). However, this further mutation on a hydrophobic amino acid in the YXXФ motif has no further effects on the constitutive internalization of the $\mathrm{Y}_{1} \Delta 32$ receptors (Fig. 6D).

\subsection{Agonist-induced internalization of $Y_{1}$ receptors having a Y347F point mutation}

In order to assess the importance of Tyr347 on the behaviour of fulllength $Y_{1}$ receptor, mutant $Y_{1}^{Y 347 F}$ receptors were constructed. On Western blots, WT $Y_{1}$ and $Y_{1}^{\mathrm{Y} 347 \mathrm{~F}}$ receptors have similar molecular weights (Fig. 7A). Y ${ }_{1}^{\mathrm{Y3} 47 \mathrm{~F}}$ receptors are coupled to adenylyl cyclase and 
A

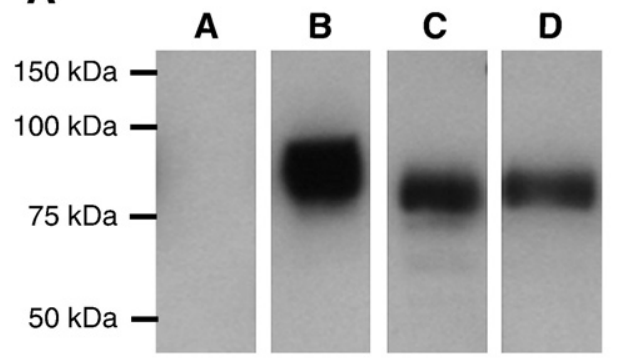

C

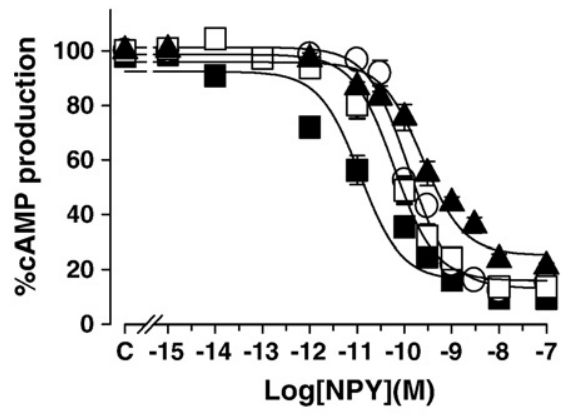

D

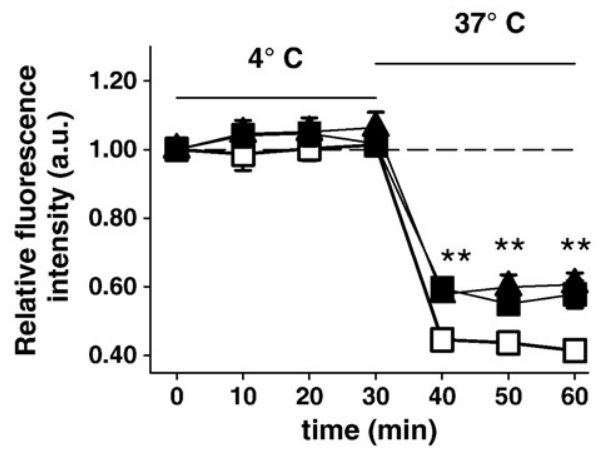

B
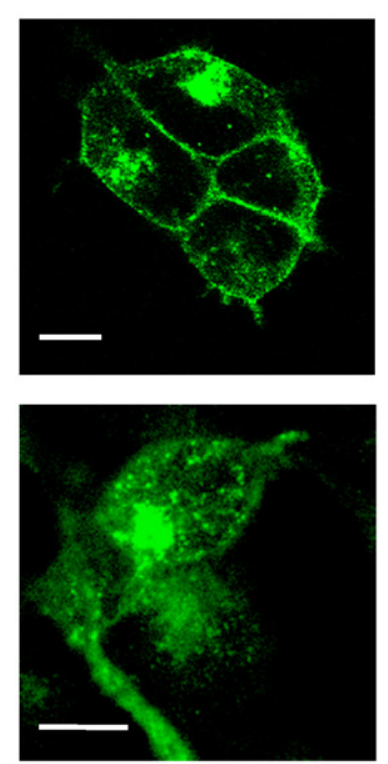

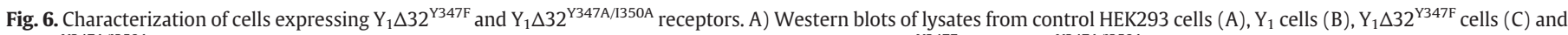

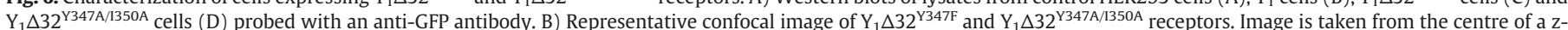

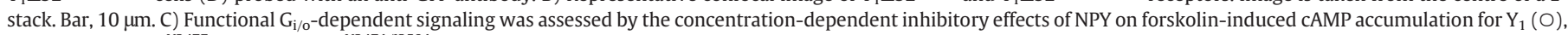

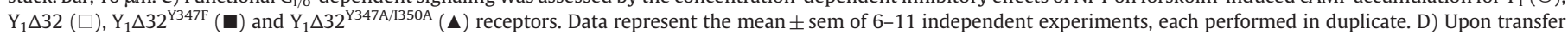

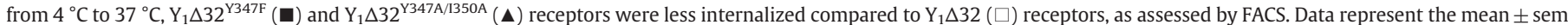
of 9-12 independent experiments. ${ }^{* *} \mathrm{P}<0.01$ vs control.

exhibit NPY sensitivity comparable to WT Y1 receptors (Fig. 7B). YY347F receptors were strongly and uniformly expressed at the plasma membrane (Fig. 7C). Upon application of NPY (100 nM), $\mathrm{Y}_{1}^{\mathrm{Y3} 37 \mathrm{~F}}$ receptors internalize. To identify the intracellular compartment(s) containing EGFP-tagged receptors after internalization, we evaluated their colocalization with transferrin receptors. After 30 min exposure to NPY, colocalized EGFP and transferrin-Texas Red signals were visualized in punctate vesicular structures (Fig. 7C, overlay, yellow signals) showing that the $Y_{1}^{\mathrm{Y} 347 \mathrm{~F}}$ receptors are endocytosed via clathrin-coated pits.

The time course of agonist-induced internalization of $Y_{1}^{\mathrm{Y} 347 \mathrm{~F}}$ receptors was also followed by fluorescence measurements [1]. After agonist challenge (100 nM NPY), both $\mathrm{Y}_{1}$ and $\mathrm{Y}_{1}^{\mathrm{Y} 347 \mathrm{~F}}$ receptors rapidly internalize (Fig. 7D). As already described [1] the decrease in fluorescence detected (Fig. 7D) reflects the pH-sensitivity of EGFP subsequent to receptor internalization in acidic endosomal compartments [1]. However, contrary to WT $Y_{1}$ receptors, no recovery to baseline was observed for $\mathrm{Y}_{1}^{\mathrm{Y} 347 \mathrm{~F}}$ receptors after $1 \mathrm{~h}$ (Fig. 7D). This lack of recovery of activated $Y_{1}^{Y 347 F}$ receptors is consistent with the existence of a new equilibrium between internalization and recycling. We have previously proposed a multicompartmental model (Fig. 7E) for internalization and recycling of $W T Y_{1}$ receptors that descibes variations of EGFP-tagged $Y_{1}$ receptor fluorescence [1]. The new steady-state distribution of $Y_{1}^{\mathrm{Y} 347 \mathrm{~F}}$ receptors can be well-described by the model (Fig. 7F, dotted line), with an endocytosis rate constant (ke1) for $\mathrm{Y}_{1}^{\mathrm{Y} 347 \mathrm{~F}}$ receptors similar to that for $\mathrm{Y}_{1}$ receptors, but with a rate constant between the early endosomal compartment and the plasma membrane (kr1) being slowed compared to $W T Y_{1}$ receptors (Table 2). These data support that Tyr347 is implicated in WT $\mathrm{Y}_{1}$ trafficking from early endosomes back to the plasma membrane.

\section{Discussion}

Our previous studies on NPY receptors [14] suggest that agoniststimulated internalization and trafficking of the wild-type $Y_{1}$ receptor is critically dependent on serine/threonine phosphorylation sites located at the extreme carboxyl terminus cytoplasmic tail of the receptor, and that precise spatial and temporal events in the endocytic phenomenon still deserve further elucidation.

Using several experimental approaches, we now show that the $\mathrm{Y}_{1} \Delta 32$ deleted receptor constitutively internalizes via a pathway involving clathrin-coated pits. Based on the lack of constitutive internalization of the further C-terminally deleted, $\mathrm{Y}_{1} \Delta 42$, receptor, we identify a region of the receptor that is implicated in trafficking. Our data indicate that a tyrosine-based motif (YETI) present in the $\mathrm{Y}_{1} \Delta 32$ receptor but absent in the $\mathrm{Y}_{1} \Delta 42$ receptor plays a key role. This conclusion is supported by the effects of the mutation of Tyr 347 into 
A

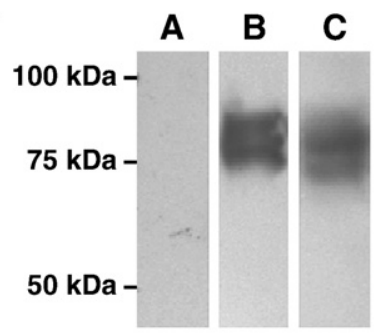

C

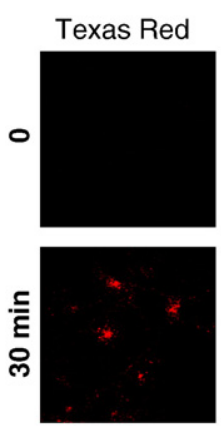

$\mathbf{E}$

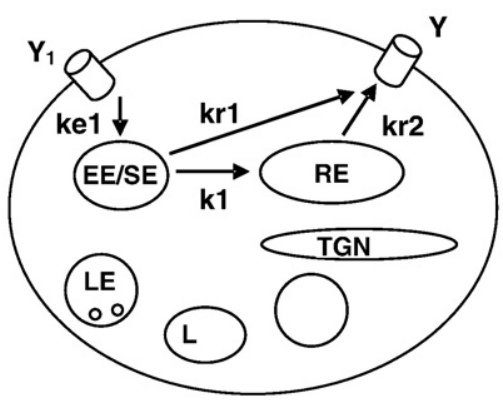

B

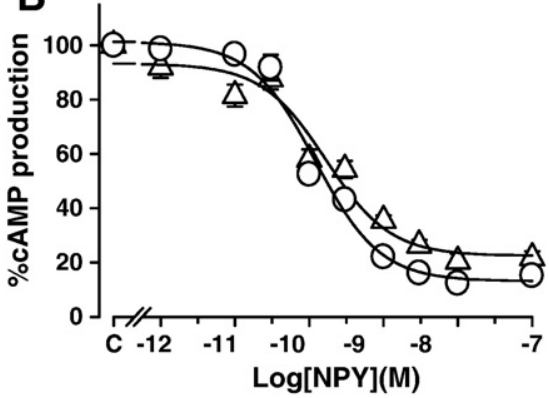

D

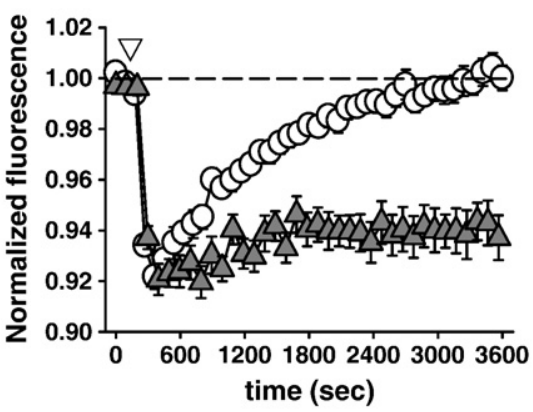

$\mathbf{F}$

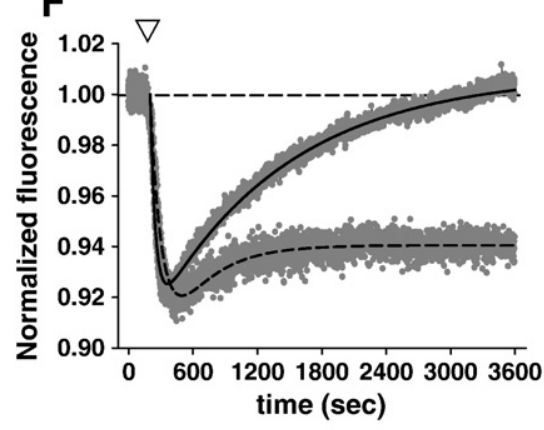

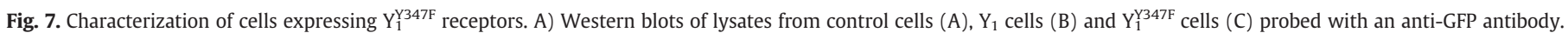

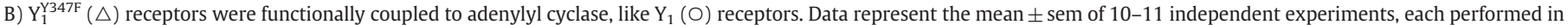

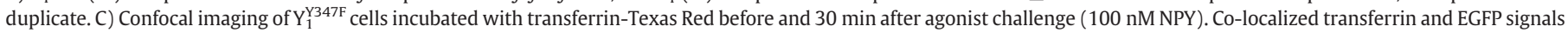

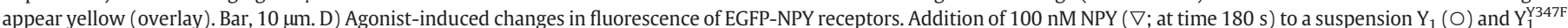

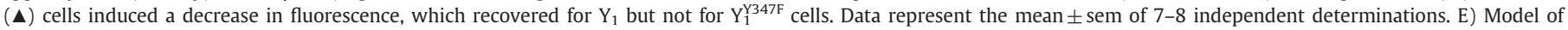

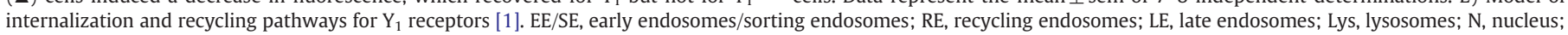

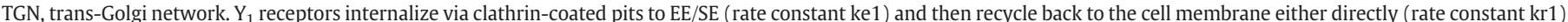

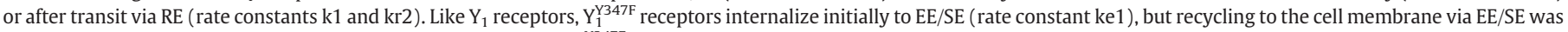

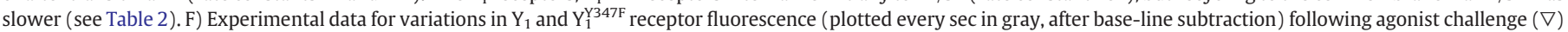
were well-fitted by the model for $\mathrm{Y}_{1}$ (black line) and $\mathrm{Y}_{1}^{\mathrm{Y} 347 \mathrm{~F}}$ (dashed black line) receptors.

Phe done in the deleted receptors which decreased constitutive internalization of $\mathrm{Y}_{1} \Delta 32^{\mathrm{Y} 347 \mathrm{~F}}$ or $\mathrm{Y}_{1} \Delta 32^{\mathrm{Y} 347 \mathrm{~A} / 1350 \mathrm{~A}}$. Moreover, mutation in the same canonical YXXФ motif partially modifies the trafficking of the activated $Y_{1}$ receptor.

Table 2

Kinetic parameters for $Y_{1}$ and $Y_{1}^{\mathrm{Y} 347 F}$ receptor trafficking. Mean fluorescence time course data (Fig. 7D) after base-line subtraction were fitted with our model [1] shown in Fig. 7E. Calculated rate constants are indicated: ke1 (from the plasma membrane to early endosomes/sorting endosomes), kr1 (from early endosomes/sorting endosomes to the cell suface), $\mathrm{k} 1$ (from endosomes/sorting endosomes to recycling endosomes) and $\mathrm{kr} 2$ (from the recycling endosomes to the cell surface). A doubling in the rate constant was considered as significant. Half-lives are given in parentheses.

\begin{tabular}{lllll}
\hline & $\mathrm{ke} 1$ & $\mathrm{kr} 1$ & $\mathrm{k} 1$ & $\mathrm{kr}$ \\
\hline $\mathrm{Y}_{1}$ & $0.17 \mathrm{~min}^{-1}$ & $0.99 \mathrm{~min}^{-1}$ & $0.05 \mathrm{~min}^{-1}$ & $0.05 \mathrm{~min}^{-1}$ \\
& $\left(\mathrm{t}_{1 / 2}=4.0 \mathrm{~min}\right)$ & $\left(\mathrm{t}_{1 / 2}=0.7 \mathrm{~min}\right)$ & $\left(\mathrm{t}_{1 / 2}=13.1 \mathrm{~min}\right)$ & $\left(\mathrm{t}_{1 / 2}=14.4 \mathrm{~min}\right)$ \\
$\mathrm{Y}_{1}^{\mathrm{Y347F}}$ & $0.12 \mathrm{~min}^{-1}$ & $0.24 \mathrm{~min}^{-1}$ & $0.03 \mathrm{~min}^{-1}$ & $0.09 \mathrm{~min}^{-1}$ \\
& $\left(\mathrm{t}_{1 / 2}=5.6 \mathrm{~min}\right)$ & $\left(\mathrm{t}_{1 / 2}=2.9 \mathrm{~min}\right)$ & $\left(\mathrm{t}_{1 / 2}=24.8 \mathrm{~min}\right)$ & $\left(\mathrm{t}_{1 / 2}=8.1 \mathrm{~min}\right)$ \\
\hline
\end{tabular}

Several lines of evidence support that the deletion mutant, $\mathrm{Y}_{1} \Delta 32$ receptor, that spontaneously traffics in and out of the cell, is mainly located in early and recycling endosomes, at $37^{\circ} \mathrm{C}$ and in the absence of agonist: i) $Y_{1} \Delta 32$ receptor co-localizes with transferrin, an early endosome tracer, but not with LysoTracker Red (a lysosome-directed pathway marker) nor with other markers of the secretory pathway, such as giantin (Golgi apparatus), or calnexin for the endoplasmic reticulum (data not shown); ii) $\mathrm{Y}_{1} \Delta 32$ receptor constitutive internalization is inhibited by sucrose which blocks clathrin-coated pits formation [22,23]; iii) Either co-transfection of $\mathrm{Y}_{1} \Delta 32$ receptor with the dominant negative Rab5aS34N mutant, or depletion of the three Rab5 isoforms (Rab5a, -5b and -5c) by using Rab5 RNA interference, decreases constitutive internalization, as expected for Rab5a being one of the regulators implicated in fusion of clathrin-coated vesicles with early endosomes [30,31]. The lack of complete inhibition of internalization of $Y_{1} \Delta 32$ by Rab5 knock down suggests that the receptor follows, in addition, other trafficking pathways that are 
clathrin-mediated but Rab5-independent. Alternatively, endogenous isoforms of Rab5 still present in cells contribute to the regulation of receptor internalization.

The $\mu 2$ subunit of the heterotetrameric adaptor, or assembly protein-2 (AP-2), recognizes proteins containing a consensus YXXФ motif at the cell surface and drives them towards rapid internalization by recruitment of the clathrin coat [19,27-29]. Interestingly, YXXФ motifs are found in the C-terminus of GPCRs [18]. For example, in the thromboxane $A_{2} \beta$ receptor (ТР $\beta$ ), a YXXФ motif appears critical for constitutive internalization while having no role in agonist-induced internalization [16]. Introduction of a tyrosine in the $\alpha$ isoform of the TP receptor (TP $\alpha)$ to create a YXXФ motif results in tonic internalization, whereas the native TP $\alpha$ receptor undergoes no constitutive endocytosis [16]. Similarly, a protease-activated receptor-1 (PAR1) truncation mutant just distal to the tyrosine-based motif constitutively internalizes, whereas two point mutations in this motif of the wild-type receptor have no effect [18]. In this work, we identify a similar tyrosine-based motif (YETI) located between the most distal 32 and $42 \mathrm{C}$-terminal amino acids only in the $Y_{1}$ receptor out of the four functional NPY receptors cloned. Replacing Tyr347 with phenylalanine in this motif decreases constitutive internalization of $\mathrm{Y}_{1} \Delta 32^{\mathrm{Y} 347 \mathrm{~F}}$ receptors, showing a contribution of the YETI sequence in the traffic of the $Y_{1}$ receptor. We further show that the contribution of the YETI sequence depends on the amino acid sequence context. Indeed, when done in the WT $\mathrm{Y}_{1}$ receptor, the mutation of Tyr 347 to Phe slows down recycling of the receptor after agonist stimulation, but does not affect spontaneous internalization level. This is in agreement with the notion that activation of the receptor unmasks binding sites for adaptor proteins. Indeed, as the full-length human $\mathrm{Y}_{1}$ receptor is not constitutively internalized in the absence of agonist, it is likely that the YETI motif is masked in the intact C-terminus of the receptor and therefore inaccessible to specific adaptor of protein sorting. Deletion of the 32 most distal amino acids thus plausibly exposes the YETI motif for interaction. Alternatively, it is possible that $Y_{1} \Delta 32$ receptor adopts a conformation that further exposes the YETI motif.

We previously reported that the human $Y_{1}$ receptor rapidly internalizes upon agonist activation via clathrin-coated vesicles as endocytosis was blocked by concanavalin A and hypertonic sucrose and internalized receptors co-localized with transferrin [1]. We were able to precisely follow EGFP-tagged receptor internalization and recycling in real-time because of the pH-dependence of EGFP fluorescence [1]. We also developed a model describing the kinetics of receptor endocytosis to early endosomes, subsequent trafficking to recycling endosomes and recycling back to the plasma membrane [1]. We found that the kinetics of both internalization and recycling of the activated full-length human $Y_{1}$ receptor are particularly fast compared to other GPCRs.

GPCRs do not use the classical tyrosine-based YXXФ motif for their agonist-induced internalization. Rather, cytoplasmic $\beta$-arrestins are adaptor proteins for the GPCR family that translocates to the plasma membrane upon receptor activation, recognizing phosphorylated amino acids in the cytoplasmic tail of GPCRs. Arrestins then serve as scaffold proteins by binding directly to the AP-2 complex and the clathrin necessary for coat formation. Recent studies have determined which serine and threonine are necessary for $\beta$-arrestins binding to the $\mathrm{Y}_{1} \mathrm{C}$-terminus receptor in response to agonist activation $[13,14,32]$. This stretch of serine/threonine is located distally compared to the YETI motif (see Table 1 ) and is thus absent in the $Y_{1} \Delta 32$ and $Y_{1} \Delta 42$ receptors.

Since $\beta$-arrestins contain sites for direct interaction with the AP-2 complex and with clathrin, it was tempting to test the hypothesis that the YETI motif in the full-length $Y_{1}$ receptor might also be a site of anchorage of the AP- 2 complex bound to $\beta$-arrestin 2 after activation, thereby influencing the kinetics of agonist-dependent internalization. However, the rate of fast internalization of $\mathrm{Y}_{1}^{\mathrm{Y} 34 \mathrm{~F}}$ receptors was not different from that of $Y_{1}$ receptors. On the other hand, unlike $Y_{1}$ receptors, recycling back to the plasma membrane for $\mathrm{Y}_{1}^{\mathrm{Y} 347 \mathrm{~F}}$ receptors was negligible. This suggests that the YETI motif does play a role in the trafficking of internalized $\mathrm{Y}_{1}$ receptors. It was recently shown that AP2 association with the $N$-formyl peptide receptor (FRP)-arrestin complex in perinuclear endosomes is required for recycling of this receptor [33]. Further work is thus necessary to determine whether indeed there is a direct interaction between the AP-2 complex and the full-length activated $Y_{1}$ receptor and whether this interaction influences the route of the receptor once internalized.

In conclusion, the constitutive internalization of $\mathrm{NPY}_{1} \Delta 32$ receptor reveals the contribution of clathrin-coated pits. Moreover, our data provide also evidence that this constitutive internalization proceeds, at least in part, via a mechanism dependent on a conserved tyrosine-based YXXФ motif located in the C-terminus and is at least in part regulated by Rab5a-associated mechanisms. Since full-length $\mathrm{NPY}_{1}$ receptor does not constitutively internalize, we propose that the C-terminal truncation directly or indirectly causes conformational changes in the receptor structure which in turn unmask determinants among which is the YETI motif.

\section{Acknowledgements}

The work was supported by the CNRS. We thank Dr. H. Herzog for NPY receptor plasmids. mRFP1 was a gift from Dr. R. Tsien and Rab5aS34N from Dr. M. Zerial. Dr. Jeremy Garwood is acknowledged for his critical reading of the manuscript. We thank E. Lacoffrette for excellent technical assistance.

\section{References}

[1] H. Gicquiaux, S. Lecat, M. Gaire, A. Dieterlen, Y. Mely, K. Takeda, B. Bucher, J.L Galzi, J. Biol. Chem. 277 (2002) 6645.

[2] T. Voisin, M. Goumain, A.M. Lorinet, J.J. Maoret, M. Laburthe, J. Pharmacol. Exp. Ther. 292 (2000) 638.

[3] M.M. Berglund, D.A. Schober, M.A. Statnick, P.H. McDonald, D.R. Gehlert, J. Pharmacol. Exp. Ther. 306 (2003) 147.

[4] S.S. Ferguson, Pharmacol. Rev. 53 (2001) 1.

[5] L. Hunyady, M. Bor, T. Balla, K.J. Catt, J. Biol. Chem. 269 (1994) 31378.

[6] Z. Huang, Y. Chen, R.A. Nissenson, J. Biol. Chem. 270 (1995) 151.

[7] W.G. Thomas, T.J. Thekkumkara, T.J. Motel, K.M. Baker, J. Biol. Chem. 270 (1995) 207.

[8] P.S. Goldman, N.M. Nathanson, J. Biol. Chem. 269 (1994) 15640.

[9] R. Jockers, A. Da Silva, A.D. Strosberg, M. Bouvier, S. Marullo, J. Biol. Chem. 271 (1996) 9355

[10] D.R. Nussenzveig, M. Heinflink, M.C. Gershengorn, J. Biol. Chem. 268 (1993) 2389.

[11] J. Chabry, J.M. Botto, D. Nouel, A. Beaudet, J.P. Vincent, J. Mazella, J. Biol. Chem. 270 (1995) 2439

[12] S.K. Shenoy, R.J. Lefkowitz, Biochem. J. 375 (2003) 503.

[13] N.D. Holliday, C.W. Lam, I.R. Tough, H.M. Cox, Mol. Pharmacol. 67 (2005) 655.

[14] M. Ouedraogo, S. Lecat, M.L. Rochdi, M. Hachet-Haas, H. Mathes, H. Gicquiaux, S. Verrier, M. Gaire, N. Glasser, Y. Mely, K. Takeda, M. Bouvier, J.L. Galzi, B. Bucher, Traffic 9 (2009) 305.

[15] C. Parnot, S. Miserey-Lenkei, S. Bardin, P. Corvol, E. Clauser, Trends Endocrinol. Metab. 13 (2002) 336.

[16] J.L. Parent, P. Labrecque, M. Driss Rochdi, J.L. Benovic, J. Biol. Chem. 276 (2001) 7079.

[17] D.P. Morris, R.R. Price, M.P. Smith, B. Lei, D.A. Schwinn, Mol. Pharmacol. 66 (2004) 843.

[18] M.M. Paing, B.R. Temple, J. Trejo, J. Biol. Chem. 279 (2004) (1947) 21938.

[19] J.S. Bonifacino, L.M. Traub, Annu. Rev. Biochem. 72 (2003) 395.

[20] R.E. Campbell, O. Tour, A.E. Palmer, P.A. Steinbach, G.S. Baird, D.A. Zacharias, R.Y Tsien, Proc. Natl. Acad. Sci. U.S.A. 99 (2002) 7877.

[21] S.L. Schmid, E. Smythe, J. Cell Biol. 114 (1991) 869

[22] G. Daukas, S.H. Zigmond, J. Cell Biol. 101 (1985) 1673.

[23] J.E. Heuser, R.G. Anderson, J. Cell Biol. 108 (1989) 389.

[24] K.G. Rothberg, Y.S. Ying, B.A. Kamen, R.G.W. Anderson, J. Cell Biol. 111 (1990) 2931.

[25] E.J. Smart, R.G. Anderson, Methods Enzymol. 353 (2002) 131.

[26] N.C. Shaner, R.E. Campbell, P.A. Steinbach, B.N. Giepmans, A.E. Palmer, R.Y. Tsien, Nat. Biotechnol. 22 (2004) 1567.

[27] H. Ohno, J. Stewart, M.C. Fournier, H. Bosshart, I. Rhee, S. Miyatake, T. Saito, A Gallusser, T. Kirchhausen, J.S. Bonifacino, Science 269 (1995) 1872.

[28] A. Nesterov, R.E. Carter, T. Sorkina, G.N. Gill, A. Sorkin, EMBO J. 18 (1999) 2489.

[29] D.J. Owen, H. Setiadi, P.R. Evans, R.P. McEver, S.A. Green, Traffic 2 (2001) 105.

[30] Z. Gaborik, L. Hunyady, Trends Endocrinol. Metab. 15 (2004) 286

[31] M. Zerial, H. McBride, Nat. Rev. Mol. Cell Biol. 2 (2001) 107.

[32] L.E. Kilpatrick, S.J. Briddon, S.J. Hill, N.D. Holliday, Br. J. Pharmacol. 160 (2010) 892

[33] B.M. Wagener, N.A. Margon, C.M. Revankar, E.R. Prosssnitz, Traffic 10 (2009) 1286 